\section{Dengue in the Americas: challenges for prevention and control}

\author{
Dengue en las Américas: desafíos para su \\ prevención y control
}

\author{
${ }^{1}$ Fundación Mexicana para \\ la Salud, México DF, México. \\ 2 Centro Regional de \\ Investigación en Salud, \\ Instituto Nacional de Salud \\ Pública, Cuernavaca, México. \\ Correspondence \\ H. Gómez-Dantés \\ Fundación Mexicana para \\ la Salud. \\ Ave. Períferico Sur no. 4809, \\ Col. El Arenal, Tepepan, \\ Mexico DF, CP. 14610 \\ hgdantes@hotmail.com
}

\begin{abstract}
Dengue is the most important vector-borne disease in the Americas and threatens the lifes of millions of people in developing countries. Imprecise morbidity and mortality statistics underestimate the magnitude of dengue as a regional health problem. As a result, it is considered a low priority by the health sector with no timely steps for effective control. Dengue is perceived as a problem of "others" (individually, collectively and institutionally), therefore responsibility for its control is passed on to others (neighbors, the community, municipality, health institutions, or other governmental agencies). With no precise risk indicators available there is little opportunity for timely diagnoses, treatment, health interventions or vector control (poor surveillance). Solutions only targeting the vector reduce the impact of interventions and there is no sustainable control. Without political commitment there are insufficient resources to face the problem. This paper discusses the challenges for prevention and control in the Americas.
\end{abstract}

Dengue; Communicable Disease Control; Disease Prevention
Héctor Gómez-Dantés 1

Janine Ramsey Willoquet 2

\section{Introduction}

Dengue is now the most important vector-borne disease in the Americas and threatens the health of millions of people that live in urban, suburban and rural environments. Clinical and public health services have been unable to diminish this disease since there is no vaccine available to prevent infection, no effective medical treatments that avert the development of severe symptoms and no sustainable control measures against the vector that guarantee protection of affected communities.

Dengue was initially identified as breakbone fever in 1790 in Philadelphia, U.S.A 1, and later spread throughout the Americas, until the Pan American Health Organization (PAHO) launched an Aedes aegypti eradication campaign to combat yellow fever in the 1950s and 1960s that came close to eliminating the vector from the continent 2 . Although the geographical distribution of the vector is similar to its distribution before the eradication campaigns ${ }^{3}$, populations during the "eradication era" were principally rural. In the last 40 years, there has been intensive urbanization due to massive migration from agricultural areas to cities. Although urbanization in Latin America and the Caribbean had already reached $41 \%$ of the population by 1950, the population living in urban areas is expected to reach between 82 and $84 \%$ by 2030; by then the Latin America and Caribbean region will be the second most urbanized 
in the world 4 . The current distribution of dengue vectors in the Americas is a fraction of their potential niche, especially with deteriorating social, environmental and economic conditions that have made vector control a more challenging goal nowadays than it was in the past.

Traditional approaches to dengue prevention and control have been inherited from the vertical programs that targeted vector elimination in domestic habitats, with the use of larvicides and insecticides in addition to breeding site elimination as the core of Aedes control strategies. The initial impact of the eradication campaign created the false impression that any vector control strategy could achieve similar reductions. During the 1990s Ae. aegypti control programmes shifted from large-scale spraying to community-based programmes, mainly due to the decentralization of health services, the breakdown of vertical control programs in the region and the lack of technical personnel. Failure to reduce efficiently vector densities have given way to the development and application of innovative approaches for community involvement, although with limited impact in the control of the overall spectrum of breeding sites in the household and peridomestic surroundings 5,6 . The purpose of this review is to describe the challenges faced by prevention and control programs in addressing a major sanitary health problem in the region.

\section{Dengue in numbers}

Dengue is the most widely distributed viral hemorrhagic fever in the world 7,8. In the 1950s, only nine countries reported dengue, while today more than 100 countries worldwide with a combined population of more than 2.5 billion are at risk of dengue infection. The average number of cases reported yearly to the World Health Organization (WHO) rose from 908 during the 1950 s to 514,139 in the 1990 s ${ }^{9}$. Around 50 million cases are estimated to occur each year causing an average 24,000 deaths worldwide, and a $100 \%$ increase is predicted in the coming two to three decades 10. During the 1980s an average 91,000 cases were reported annually by 25 countries. During the period from 2000 to 2006 , an average of 545,000 cases was reported every year by 44 countries. Dengue statistics should be considered a proxy for real incidence. The upward trend and cyclical nature of dengue epidemics every three to five years, occurs at different moments in every country (Table 1). Although epidemic outbreaks are not temporally homogenous, reintroductions from one country to another also provoke increases in the risk of severe dengue infection ${ }^{11}$. The first major dengue hemorrhagic epidemic in the Americas occurred in Cuba in 1981 and was caused by dengue 2 virus. From 1981 to 1996, 42,246 dengue

Table 1

Dengue incidence (rates per 100,000 inhabitants) in selected countries, 2000-2006.

\begin{tabular}{|c|c|c|c|c|c|c|c|}
\hline Country & 2000 & 2001 & 2002 & 2003 & 2004 & 2005 & 2006 \\
\hline Argentina & 4.6 & 0.03 & 0.6 & 0.4 & 8.7 & 0.1 & 0.5 \\
\hline Bolivia & 0.88 & 14.7 & 74.3 & 327.4 & 369.5 & 222.1 & 102.0 \\
\hline Brazil & 136.1 & 239.4 & 452.4 & 198.1 & 65.4 & 118.1 & 200.8 \\
\hline Colombia & 53.8 & 272.7 & 210.3 & 258.7 & 135.4 & 149.9 & 180.7 \\
\hline Costa Rica & 434.6 & 818.2 & 314.5 & 606.3 & 290.0 & $1,165.2$ & 345.1 \\
\hline Cuba & 1.2 & 101.6 & 26.7 & 0 & 0 & 0.7 & $?$ \\
\hline Dominican Republic & 40.7 & 42.3 & 37.6 & 72.5 & 27.6 & 33.7 & 72.3 \\
\hline Ecuador & 181.4 & 84.8 & 45.3 & 80.1 & 47.8 & 94.2 & 45.1 \\
\hline El Salvador & 51.7 & 17.1 & 286.0 & 116.2 & 201.0 & 226.3 & 307.8 \\
\hline Guatemala & 79.1 & 38.6 & 65.0 & 57.8 & 54.3 & 54.3 & 24.5 \\
\hline Honduras & 210.4 & 138.0 & 490.8 & 251.8 & 303.7 & 286.6 & 128.3 \\
\hline Mexico & 21.9 & 6.2 & 9.8 & 5.0 & 8.2 & 16.8 & 27.2 \\
\hline Nicaragua & 144.2 & 40.4 & 41.4 & 53.7 & 19.9 & 31.6 & 25.9 \\
\hline Panama & 11.1 & 53.3 & 24.5 & 10.1 & 12.9 & 137.9 & 145.6 \\
\hline Paraguay & 441.8 & 0.7 & 33.2 & 2.4 & 2.9 & 7.2 & 75.8 \\
\hline Peru & 21.4 & 89.4 & 34.0 & 13.9 & 37.5 & 24.4 & 14.2 \\
\hline Puerto Rico & 62.9 & 132.4 & 73.5 & 94.5 & 83.2 & 144.3 & 77.0 \\
\hline Venezuela & 87.3 & 337.7 & 152.9 & 109.6 & 124.6 & 171.3 & 149.9 \\
\hline
\end{tabular}

Source: Pan American Health Organization. http://www.paho.org/spanish/ad/dpc/cd/Dengue.htm (accessed on Feb/2007). 
hemorrhagic fever cases were reported in several countries, although $90 \%$ of these cases were from Venezuela (52\%), Cuba (24\%), Colombia (9\%), Nicaragua (6\%) and Mexico (3\%). During the 2000-2006 period, 85,331 dengue hemorrhagic fever cases were reported from Colombia and Venezuela $(61 \%)$, while $16 \%$ of cases were from Mexico (Table 2).

Although there is an overall ratio of 45 dengue fever cases reported for every dengue hemorrhagic fever case detected, the ratio of dengue /dengue hemorrhagic fever cases reported in Brazil (468) and Costa Rica (396) is very different from those reported in Honduras (17), Venezuela (13), Colombia (10) or Mexico (7). This variation is principally due to under-reporting of dengue cases in the countries with the lowest dengue/ dengue hemorrhagic fever ratio and/or lack of severe dengue diagnosis in the countries with high ratios. In both scenarios, passive surveillance of dengue fever cases and failure of clinical diagnostic capacity hamper precise measurements of the magnitude and trend of this health problem and illustrate the problems faced by all surveillance systems: incomplete, inopportune and imprecise information (Table 2).

\section{A practical framework for prevention and control}

Dengue epidemiology has changed with time and the evolving clinical picture, social and cultural environments, vector control strategies and surveillance capabilities in the region must be addressed in an integrated manner, due to the complexity of factors involved in transmission dynamics, risk assessment and control potential. The purpose of the present framework (Table 3) is to describe what we know about dengue, the challenges associated with major transmission determinants, the problems faced by clinicians for dengue diagnosis and treatments of complications; the laboratory infrastructure required to support clinicians and public health workers, the inconveniences faced by surveillance systems, and the unmet needs of prevention and control strategies.

Dengue hemorrhagic fever cases in selected countries, 2000-2006.

\begin{tabular}{|c|c|c|c|c|c|c|c|c|c|}
\hline Country & 2000 & 2001 & 2002 & 2003 & 2004 & 2005 & 2006 & Total & $\begin{array}{c}\text { Dengue fever/ } \\
\text { dengue hemorrhagic } \\
\text { fever ratio }\end{array}$ \\
\hline Argentina & 0 & 0 & 0 & 0 & 0 & 0 & 0 & 0 & 0 \\
\hline Bolivia & 73 & 0 & 1 & 47 & 25 & 10 & 1 & 157 & 137,3 \\
\hline Brazil & 59 & 679 & 2,607 & 713 & 77 & 433 & 628 & 5,196 & 467,7 \\
\hline Colombia & 1,819 & 6,563 & 5,269 & 4,878 & 2,815 & 4,306 & 5,379 & 31,029 & 9,8 \\
\hline Costa Rica & 4 & 37 & 27 & 69 & 11 & 52 & 64 & 264 & 395,7 \\
\hline Cuba & 0 & 69 & 12 & 0 & 0 & 0 & $?$ & 81 & 180,9 \\
\hline Dominican Republic & 58 & 4 & 76 & 252 & 136 & 84 & 230 & 840 & 33,2 \\
\hline Ecuador & 3 & 55 & 158 & 416 & 64 & 334 & 173 & 1,203 & 61,8 \\
\hline El Salvador & 411 & 54 & 405 & 138 & 154 & 207 & 245 & 1,614 & 50,1 \\
\hline Guatemala & 42 & 4 & 47 & 22 & 39 & 32 & 4 & 190 & 228,6 \\
\hline Honduras & 314 & 431 & 863 & 458 & 2,345 & 1,795 & 636 & 6,842 & 17,4 \\
\hline Mexico & 50 & 191 & 1,429 & 1,419 & 1,959 & 4,255 & 4,477 & 13,780 & 6,9 \\
\hline Nicaragua & 636 & 458 & 157 & 235 & 93 & 177 & 52 & 1,808 & 10,2 \\
\hline Panama & 3 & 7 & 5 & 0 & 4 & 2 & 5 & 26 & 287,1 \\
\hline Paraguay & 0 & 0 & 0 & 0 & 0 & 0 & 0 & 0 & 0 \\
\hline Peru & 0 & 251 & 13 & 15 & 35 & 16 & 4 & 334 & 188,6 \\
\hline Puerto Rico & 24 & 36 & 23 & 5 & 11 & 19 & 7 & 125 & 210,7 \\
\hline Venezuela & 2,186 & 6,541 & 2,979 & 2,246 & 1,986 & 2,681 & 2,476 & 21,095 & 13,4 \\
\hline Americas & 5,667 & 15,500 & 14,374 & 10,994 & 9,810 & 14,557 & 14,429 & 85,331 & 44.8 \\
\hline
\end{tabular}

Source: Pan American Health Organization. http://www.paho.org/spanish/ad/dpc/cd/Dengue.htm (accessed on Feb/2007). 
Practical framework for dengue prevention and control.

\begin{tabular}{|c|c|c|c|c|c|c|c|}
\hline \multirow{2}{*}{$\begin{array}{l}\text { Primary determinants } \\
\text { Environmental }\end{array}$} & \multicolumn{7}{|c|}{ Health services determinants } \\
\hline & $\begin{array}{l}\text { Biological } \\
\text { risk factors }\end{array}$ & Clinical picture & $\begin{array}{c}\text { Risk } \\
\text { perception }\end{array}$ & Diagnosis & Treatment & Surveillance & $\begin{array}{l}\text { Prevention } \\
\text { and control }\end{array}$ \\
\hline $\begin{array}{l}\text { Physical: temperature, } \\
\text { rainfall, altitude, } \\
\text { vegetation, soil use/ } \\
\text { Global: urbanization, } \\
\text { population growth, } \\
\text { migration; travel, } \\
\text { industry responsibility } \\
\text { (non-recyclable } \\
\text { products)/Local: house } \\
\text { conditions, Public services } \\
\text { infrastructure, water } \\
\text { management, education, } \\
\text { social networks/ } \\
\text { Knowledge, attitudes } \\
\text { and perceptions }\end{array}$ & $\begin{array}{c}\text { Vector: } \\
\text { competence } \\
\text { and capacity/ } \\
\text { Virus: serotypes, } \\
\text { virulence, } \\
\text { sequence of } \\
\text { infections/ } \\
\text { Host: age, sex, } \\
\text { immune } \\
\text { response, } \\
\text { herd immunity } \\
\text { nutrition, race, } \\
\text { genetic traits }\end{array}$ & $\begin{array}{c}\text { Severe fever } \\
\text { Fever with } \\
\text { hemorrhage } \\
\text { Dengue hemorrhagic } \\
\text { fever/dengue } \\
\text { shock fever } \\
\text { (grades I, II, III, IV) }\end{array}$ & $\begin{array}{l}\text { Common } \\
\text { disease self } \\
\text { limiting }\end{array}$ & $\begin{array}{c}\text { Very low } \\
\text { Low }\end{array}$ & $\begin{array}{c}\text { Specialized } \\
\text { clinical care } \\
\text { (fluid } \\
\text { replacement) }\end{array}$ & $\begin{array}{c}\text { Not perceived } \\
\text { silent } \\
\text { transmission } \\
\text { Poorly recognized. } \\
\text { Passive detection } \\
\text { Partially reported } \\
\text { (Passive and active) } \\
\text { Incomplete } \\
\text { morbidity and } \\
\text { mortality statistics }\end{array}$ & $\begin{array}{l}\text { Infestation } \\
\text { indices } \\
\text { (opportunity \& } \\
\text { productivity) } \\
\text { Breeding site } \\
\text { classification, } \\
\text { Source reduction; } \\
\text { chemical, } \\
\text { biological, } \\
\text { behavioural } \\
\text { interventions } \\
\text { Emergency } \\
\text { control: } \\
\text { source } \\
\text { reduction, } \\
\text { insecticide } \\
\text { spraying, } \\
\text { social } \\
\text { mobilization }\end{array}$ \\
\hline Challenges & Pathogenesis & $\begin{array}{c}\text { Assessment } \\
\text { of WHO } \\
\text { definition }\end{array}$ & $\begin{array}{c}\text { Risk awareness. } \\
\text { Behavior } \\
\text { change }\end{array}$ & $\begin{array}{l}\text { Identific } \\
\text { case m }\end{array}$ & $\begin{array}{l}\text { tion of at risk po } \\
\text { nagement, labor } \\
\text { inical infrastruct. }\end{array}$ & $\begin{array}{l}\text { ulations, } \\
\text { tory and } \\
\text { e }\end{array}$ & $\begin{array}{c}\text { Vaccine, effective } \\
\text { vector control, } \\
\text { sustainable } \\
\text { community } \\
\text { prevention and } \\
\text { interventions }\end{array}$ \\
\hline
\end{tabular}

\section{Major determinants of dengue transmission}

\section{Environmental}

Dengue is considered a disease of the tropics due to its most recent geographic distribution, despite the fact that Ae. aegypti and breakbone fever were originally reported in temperate areas such as Philadelphia in the late $18^{\text {th }}$ century. The perception of dengue as a tropical disease derives from its relationship with climate variables such as heavy rainfall, high temperatures, humidity and vegetation, which define the vector's ecological niche and are typically found in Southeast Asian countries where dengue and dengue hemorrhagic fever were initially recognized. The vector is extremely sensitive to meteorological conditions and seasonal variations which affect its distribution and abundance in predictable annual cycling. Temperature influences dengue transmission by affecting vector density patterns, blood feeding habits and virus propagation in the mosquito 12,13 .

Seasonal occurrence of dengue transmission can be attributed to the increase in breeding sites available during the rainy season or the need to accumulate water during droughts or dry seasons 14 . While these factors influence the density, productivity and stability of larval sites, its association with transmission patterns usually lags several weeks 15,16. Global climate changes have created great concern about the emergence of dengue in more temperate areas (with controversial conclusions), although predictions of dengue outbreaks in regions now free of the transmission, remain to be validated 17,18 . 


\section{- Global determinants}

Multiple factors favour viral transmission to humans by a mosquito vector: human population growth, rural-urban migration, and unplanned urbanization, characterized by the inadequacy of basic urban infrastructure with substandard housing conditions and insufficient water supply, sewage and waste management systems 19 . In addition, the uncontrollable massive proliferation of non-recyclable products (discarded plastic, metal and glass containers, tires) has resulted in a deteriorated environment, favouring an increase in mosquito breeding sites.

Today, cities are better communicated by more and faster means of transport, thereby creating urban networks where risks are easily disseminated from local to international settings. Population movements (migration and tourism) are important vehicles for spreading the serotypes and strains, and the co-circulation of multiple serotypes increases the potential for the emergence of dengue hemorrhagic fever/dengue shock syndrome 20 . Routes of global trade provide natural sources for vector dispersion 21 , while a global economy means that no country is completely immune to the risks.

Dengue transmission is highly concentrated in urban settings, especially in those below a certain altitude range, above an average annual temperature, with a high population density and deficient public services infrastructure 22,23. However widespread distribution of dengue infection in rural areas is evident as surveillance systems and access to health services improve in those areas. The logistics of vector control strategies in disperse and low-populated areas is therefore complicated. The higher rates found in rural areas in Thailand are linked to a higher dependence on water storage during the dry season 24 . Increase in dengue/dengue hemorrhagic fever among rural populations has also been observed in Central and South America, with similar prevalence rates in some urban and rural populations 25. A study from the Gulf coast of Mexico showed that $85 \%$ of the communities reporting dengue infection during the $1995-1998$ period were rural and $65 \%$ of those were classified as extremely poor according to socioeconomic indicators 26. Despite its wide dispersion in rural areas, transmission primarily occurs in urban environments.

Ae. aegypti is an urban mosquito that is domesticated where population density, proximity to dwellings, and large and continuous production of breeding sites, all provide ideal conditions for transmission. It is highly dependent on the existence of man-made artificial contain- ers widely used to deal with deficiencies and inconsistencies in domestic water supply. This situation must be analyzed not only from the individual perspective but also as a social problem where every member of the community has a role and a responsibility. Special emphasis should be placed on industry's role in producing new types of containers which may be massively introduced into the community, with no provision for adequate disposal. The burden of control strategies has shifted to the community, even though risk is influenced by factors that are external to the community's environment. Control strategies have focused responsibility only on the community, without regulating the role of industry, and its social responsibility regarding environmental health.

\section{- Local determinants}

Dengue should not be considered a poverty-related disease because it affects wealthy neighbourhoods as well, although the magnitude of risk can be moderated by the use of housing materials such as screens in doors and windows 27,28 . In Taiwan, it was estimated that $63 \%$ of dengue infections could be eliminated if everyone lived in adequately screened homes 29 . Even in comparable areas both with high vector abundance in an ideal climate such as the Mexican-Texas border, the primary determinant for dengue prevalence was socioeconomic. Improved housing conditions (the use of air conditioners) limited transmission even when Ae. aegypti infestation rates were remarkably high on both sides 30 . Dengue infection rates in Southeast Asia have been declining, in part due to strong economic growth in many countries, and to improved housing standards and control programs, which have reduced vector populations 31. Dengue transmission by Ae. aegypti has been associated with poor hygiene, and poor socioeconomic and literacy levels, especially for female heads of households $32,33,34$.

\section{Biological risk factors}

The complex relationship between climate variables, mosquito abundance, human host density, and viral serotype define the potential heterogeneity of disease transmission patterns. Vectors need to contact infected and susceptible hosts, and therefore abundance, dispersion, mortality, genetic and tissue susceptibility to infection, feeding behaviour, and the extrinsic incubation period are the most important variables for dengue transmission dynamics 35,36,37,38. 
Genetic analyses of dengue viruses have been useful to monitor the transmission of viral genotypes associated with the increase of severe cases ${ }^{39}$. Dengue 2 (DEN-2) viruses belonging to the Southeast Asian genotype appear to be better adapted to mosquito transmission and are associated with more severe clinical outcomes. They are apparently displacing the American genotype of DEN-2 viruses in some regions of Latin America 40

Universal susceptibility to infection implies natural risk for all exposed populations even though most people suffer only mild fevers when infected. Severe dengue develops where endemic transmission and co-circulation of different serotypes occurs. The role of age, sex, race and genetic background in the host population interact in different ways depending on the history of dengue in each country or region. The age distribution of dengue hemorrhagic fever cases in the Americas is different from that observed in Asia. Cases in Cuba and Venezuela include all age groups, although two thirds of the fatalities have been in children under the age of 15. Studies in Brazil describe a mean age range of 3145 years. In Puerto Rico the mean age changed from under 15 years to 38 years between 1986 and 1991. Nevertheless, elderly groups in Puerto Rico had less haemorrhagic symptoms, similar case fatality rates, and were hospitalized as often as infants 41 .

Infection serotype and previous exposure history to other dengue serotypes are known to influence disease severity ${ }^{42}$. Primary infection with any of the four dengue serotypes is usually associated with mild disease, while increased susceptibility to dengue hemorrhagic fever/ dengue shock syndrome occurs if the individual is infected with a second heterologous serotype. The immune basis for this hypothesis suggests that antibodies developed during the primary infection decline to sub-neutralizing levels and instead of mediating viral clearance, assist the new virus in infecting host macrophages, a phenomena known as antibody-dependent enhancement 43 . Nevertheless, dengue hemorrhagic fever resulting from primary infections has increased over time from $1 \%$ in 1978 to $14 \%$ in 1997, but is associated with milder clinical symptoms 44 . The risk of developing dengue hemorrhagic fever has been estimated at only 1-125 severe cases out of every 1,000 dengue infections in children 45 and it occurs 15 to 80 times more frequently in individuals experiencing a secondary infection although the reasons are still not clearly understood 46,47 .

\section{Health services determinants}

\section{Clinical profile}

Infection with any virus serotype can produce a wide spectrum of clinical illness, ranging from asymptomatic nonspecific febrile syndrome, to severe and fatal hemorrhagic disease. While most patients go through an asymptomatic phase, those who have signs and symptoms develop a self-limiting illness considered benign that runs unapparent or mild in children. Dengue hemorrhagic fever and dengue shock syndrome are life-threatening illnesses associated with hemorrhage, thrombocytopenia and increased vascular permeability. The severe limit of the dengue spectrum is characterized by the sudden onset of hemoconcentration and hypoproteinemia and fever defervescence, but it has been difficult to adhere to the WHO case definition of hemoconcentration in certain settings, since there is no precise test that can accurately predict impending dengue vascular leakage, hipovolemia and shock 48 . An important aim of the WHO classification system is to allow prompt identification of patients who are at greatest risk for developing severe dengue complications, thereby facilitating triage and appropriate use of clinical resources. Strict application of clinical criteria, however, underestimates the number of severe cases. Unfortunately, the WHO definition requires multiple and repeated clinical tests that are not available in countries with limited resources. Omission of the tourniquet test would impede detection of Grade I dengue hemorrhagic fever cases that represent $15-20 \%$ of all dengue hemorrhagic fever cases. Even early treatment is incompatible with diagnostic criteria, since appropriately hydrated cases will not present hemoconcentration 45 . In Nicaragua, only $30 \%$ of infants in a study fulfilled strict dengue hemorrhagic fever/dengue shock syndrome criteria and the tourniquet test had a low sensitivity 49 . Approximately $82 \%$ of Vietnamese children in shock were correctly identified using the narrow WHO classification system 50 , although the tourniquet test had a sensitivity of only $41.6 \% 51$. Differences between disease patterns from Southeast Asia and the Americas can be traced to clinical practice, particularly to the failure of clinicians in the Americas to collect appropriate data to fulfil the requirements of the WHO case definition 52 . In Asia, better case management and intensive national programs to educate parents and medical staff improved early care and avoidance of over hydration of dengue hemorrhagic fever/dengue shock syndrome patients 43 . 


\section{Risk perception and diagnosis}

Dengue is not a medical priority for affected communities, since their social, economic and environmental priorities are more compelling than an inadvertent, mild fever solved by self medication which rarely requires clinical attention. At the family level, dengue is considered mild, and a common disease which does not require investment in time or money in health care, except when symptoms are severe. Even when studies have demonstrated that people in endemic countries recognized the disease and its link to the vector, control practices are not equivalent to knowledge about the disease or risk perception. In most regions, there is no appreciation or sense of urgency or risk associated with the worldwide deteriorating dengue situation. Cultural and practical issues related to water management at the domestic, community and urban levels are crucial to understanding risk assessment, and hence the development of effective control strategies. It is a common belief that control is only the responsibility of government agencies (vector control programs), which undermines individual actions, and a sense of community responsibility 53 .

When faced with a dengue fever case, physicians require support from laboratories to confirm infection using paired blood samples, and/or to classify the stage and severity of clinical findings. In addition to the problem of inappropriate clinical diagnoses by unskilled physicians, there is an absence of quality serological diagnoses and viral isolation in endemic areas. Due to intensive dengue transmission in the region, countries are compelled to strengthen their laboratory capabilities in support of surveillance activities. By 1996, only 53 laboratories in 14 countries had serologic diagnostic capabilities using IgM antibodies; only 20 had resources to perform virus isolation, and only 11 used molecular techniques. Quality control performed from 1996 to 2001 demonstrated that only $87 \%$ of laboratories had excellent performance in their diagnostic capabilities with problems ranging from the irregular provision of antigens, dependency on the regional centers for kit distribution, different sensitivity among serologic tests, and the limited use of more specific diagnostic techniques 54 .

\section{Treatment}

Dengue fever cases are usually treated with antipyretic drugs and analgesics (salicylates are counter indicated). Due to the progressive nature of the illness, repeated assessment during the febrile period may be necessary, with closely monitored intravenous fluid replacement as the cornerstone of severe case management. Severe dengue requires expert care and hospitalization, even though the lack of clinical predictors of severe disease complicates diagnosis and timely treatment. The case fatality rate may be kept below $1 \%$ where skilled staff and facilities are available. In poor countries, it can be as high as $10 \% 55$.

\section{Surveillance}

Dengue is a mandatory reportable disease that must be reported to the nearest epidemiology unit. The clinical spectrum of the infection, however, undermines surveillance activities, for several reasons. First, the most cases are asymptomatic and go undetected. The prevalence of asymptomatic children in Costa Rica varied from $2.9 \%$ in San Jose to $36.9 \%$ in the coastal region 56. During the 1970's, dengue swept through Colombia causing an extensive epidemic where more than half a million cases were estimated but most occurred silently for most of the period. The silent epidemic in the city of Salvador, Brazil, between 1998 and 1999 was estimated to have infected around 560,000 individuals, while the official notification system only recorded 360 cases 57 . Asymptomatic cases and under-reporting contributed to a false panorama of dengue in these areas. Similar results were reported in central Brazil, where seroprevalence surveys estimated 340,000 cases and official reports only contained 9,544 32 .

Secondly, a large proportion of infected individuals have the mild form of the disease, which is perceived as not serious enough to warrant health care assistance. Dengue cases are misdiagnosed by medical personnel as a febrile syndrome, and therefore go unreported. When dengue fever is identified, regulatory guidelines require paired blood samples to confirm diagnosis, therefore only a small proportion of cases are diagnosed, confirmed and reported. Dengue statistics in the region under-report mild and classic cases, and are not designed to recognize all but the most severe cases. Confirmed cases face the same technical caveats as all laboratory tests required to comply with the strict WHO classification criteria. This situation explains why during 2006, only $4 \%$ of the total number of dengue cases were confirmed by laboratory tests (PAHO).

Finally, official notification systems register cases reported by the primary health care system, which is used mainly by uninsured populations. The diversity of public health institutions in each country complicates opportune case notification to surveillance and control programs. The 
private health sector rarely complies with case notification, and consequently, important data is lost from a variety of health providers. Combined, these undermine coverage and access to the surveillance system. A dengue prevention program faces multiple operational problems due to the lack of sensitive identification of atrisk populations, and identification of infected versus diseased patients.

\section{Prevention and control}

Ae. aegypti is adapted to domestic and peridomestic environments, and breeds in different types of artificial containers, which are specifically used for water storage due to insufficient municipal supply. Even in areas with a continuous potable water supply, Ae. aegypti densities can be found in clean containers such as flower vases and fountains. Traditional entomological indices such as House or Premise Index (HI), Container Index (CI) and Breteau Index (BI), are used to monitor Ae. aegypti, although attempts to associate them with dengue transmission have failed due to the fact that these indices measure prevalence, not abundance, and because they do not discriminate between capacity or productivity. Other indices have been proposed to address the issue of productivity (Larval Density Index, the Stegomyia Index and the Stegomyia Larval Density Index), but are labor intensive and impractical 58. Pupal surveillance of Aedes vectors has been proposed as a more accurate measure of female mosquitoes as complementary to traditional larval surveillance. The Premise Condition Index offers a rapid assessment method of selected households for surveys, does not require larval identification or infested container and larval counts, and can be done from the outside and is quick. Its primary limitation is that it does not consider indoor breeding risks 59 .

While source reduction is considered the most effective measure of vector control, it is important to distinguish sources that are controllable from those that are disposable, and those that are indoors versus outdoors. In Singapore, $79 \%$ of total breeding sites were indoors 29 . In Fiji, surveillance and control strategies failed to define key container types, e.g. tyres and drums, which were responsible for most of the Aedes being produced 60 . Studies in El Salvador have demonstrated that infested discarded cans, plastic containers and tire casings were risk factors for dengue infection with abundance-attributable fractions of $4 \%, 13 \%$ and $31 \%$, respectively 61 .

Reduction of mosquito breeding in household water containers using larvicides, predatory crustaceans, or elimination of discarded containers, and control of adult mosquitoes by spraying insecticides, requires continuous efforts by the communities, which are difficult to sustain, and for which effectiveness requires validation. Options for control, such as insecticide-treated window curtains, water container covers and controlled-release insect growth regulators may contribute to reduce densities of dengue vectors and dengue transmission 62 . Decreasing the carrying capacity of the mosquito's environment using frequent reduction of the vector breeding sites seems to be the most effective way to control disease but good entomological indices are required to monitor transmission risk, and evaluate the impact of different control strategies, whether physical, biological, chemical or behavioural.

Our ability to control Ae. aegypti is also limited since larvicides have low coverage in terms of the large pool of breeding sites present in any urban environment. Growing reluctance on the part of residents to accept their use in potable water, their expense, the increase in non essential water holding containers in the environment, and the increasing frequency of locked residences during the day has resulted in infrequent applications and inadequate coverage which affect long-term suppression 63 . Insecticides are short in reach when it comes to effective penetration into the vector's resting places, and they are short lived in relation to female adult mortality. Studies conducted in Asia and the Americas, indicate that after the application of Ultra Low Volume (ULV), the adult population of mosquitoes returned to pretreatment levels within two weeks, and even with multiple applications, the impact on incidence was minimal 64 .

Aside from these technical problems, there is no public health program with sufficient human resources to deal with all households in urban centers (short response capacity). National programs are under-funded, poorly managed and operate in isolation from other health care delivery elements. Field workers are poorly motivated and supervised, are underpaid and lack communication skills. Unfortunately, during low transmission periods, most individuals as well as government agencies lose interest in mosquito control, and hence subsequent vector population increases. Dengue control has been approached as a community responsibility by the public health community, and exclusive reliance on the community to assume full responsibility for vector control activities has been stressed even though it is a problem which requires resources and financing from different governmental agencies and municipal actors outside the health sector. 
The domestic urban environment creates new risks associated with accelerated urbanization processes and this risk challenges the countries to respond with basic sanitary infrastructure. Intersectoral and multidisciplinary vector control programs are needed and several community based dengue control interventions have been reported from a wide variety of ecological and social environments, including: communication campaigns, educational initiatives, behavioral change, biological control efforts, integrated control projects and a mixture of the above strategies. Interventions that rely on educational strategies only, have less impact on behavior and entomologic indices 65 . The evidence to show that community-based dengue control programmes alone, or those implemented in combination with institutional control activities, can enhance the effectiveness of dengue control programmes is weak 66 .

Behavioral changes can help reduce the infestation of domestic containers, if individual community and institutional practices are correctly targeted. Changing behavior requires mobilizing social networks and organizations, as well as implementing firm public policies. A new relationship between governmental institutions and individuals is required and programs should be designed based on local sanitation structure, as well as community organization and roles for different family members. Programs should incorporate epidemiological surveillance, community participation, management of the environment and basic public services, case management, education, and effective vector control and training. Sustained dengue control requires partnerships among donors, the public sector, civil society, non-governmental organizations, the private sector, and the interactions between politicians, public health personnel, administrators, engineers, urban planners, and environmental groups, in order to strengthen existing intersectoral management structures in support of community actions 67,68 .

\section{Challenges}

Countries in the Americas now face the irrefutable fact that social, economic and environmental conditions have converged to establish dengue as a major health threat to their populations. The enormous investment required for urban infrastructure in developing countries, will hardly be available in the near future, although adaptation of health services to avoid or prevent dengue transmission is feasible. Basic research must provide a better understanding of the immune response, the antibody dependent enhancement mechanisms, virulence factors for the different genotypes and pathogenic pathways of severe dengue infection. Understanding the changing and severe clinical profile of dengue infection must be clarified for the development of safe vaccines and effective drugs for treatment. Clinical diagnoses of dengue cases will benefit and improve the identification of at-risk populations for severe dengue, although a strong laboratorybased surveillance system, intensive training of medical staff and strong medical infrastructure support for clinical diagnosis in endemic and high risk areas are also essential components.

Without vaccines, effective drugs, or sensitive diagnostic tests, the only available response to reduce disease severity and case fatality is clinical management through enhanced care supported by accessible, sensitive and specific useful diagnostic tests. These tools will help identify warning signs for severe disease and evidenced-based criteria for treatment procedures standardization 69. The current WHO/dengue hemorrhagic fever definition is an epidemiological tool to collect public health data on the incidence of symptomatic infection, as well as disease severity. This definition should be simple and reproducible, use readily available information, and should be applicable to the majority of cases without modification or reinterpretation. The current definition is not equally useful in all clinical care or epidemiological situations, nor does it reflect current practices in case treatment, hospital laboratory, and diagnostic methods 43 .

An ideal dengue vaccine must be tetravalent, in order to protect against infection from all four serotypes. Recent initiatives focus predominantly on recombinant strategies based on infectious clone technology, DEN antigen-encoding viral and plasmid vectors and recombinant DEN antigens. Several multivalent dengue vaccines are in various stages of development, but none is close to regulatory approval. Live attenuated tetravalent dengue vaccines are being developed either through multiple passages of the virus in animal tissues and for cell culture, or through viral mutation combined with chimerization. The risk of developing severe dengue during a secondary infection has major implications for vaccination policy, since vaccines developed against one or two strains could theoretically prime populations for future epidemics of dengue hemorrhagic fever/dengue shock syndrome 70 . The potential for immunization-mediated enhanced disease has given rise to the current goal, which is to produce solid immunity against all four serotypes with one or two vaccine doses. Once a safe vaccine becomes available for wide-scale evaluation, it 
needs to be tested to measure protective efficacy and safety, since a major problem will be to differentiate potential vaccine-induced immune enhancement diseases. The 50 million dollars of support granted by the Bill and Melinda Gates Foundation to develop a paediatric dengue vaccine does not necessarily guarantee that a vaccine may be available for poor children in dengue endemic countries in the near future 71 .

The development of improved entomological surveillance methods is crucial for timely vector control. Entomological indices must measure transmission risk thresholds and provide precise information to evaluate physical, biological, chemical or behavioural interventions. Breeding containers must be identified according to their abundance, potential productivity and control activities required for elimination of breeding risks (controllable vs. disposable). Productivity of key premises or breeding containers is an important issue since a low proportion of positive premises and containers are responsible for high productivity. As a result, limited resources are available to control high risk areas 72 . Effective vector control should be based on timely detection of entomological risks which can then be tackled through community participation schemes supported by governmental actors and social stakeholders.

Community based health projects need to find the ingredients necessary to generate a continuous action to promote changes in behavior since they are expected to modify the environment where the problem arises. Sustainability

\section{Resumen}

El dengue es la enfermedad transmitida por vector más importante en las Américas, que amenaza la vida de millones de personas. Las cifras subestiman la magnitud del problema y el dengue no figura como prioridad para las autoridades en salud y no se identifica como problema (baja percepción de riesgo), por lo que las medidas para el control se realizan tardiamente. El dengue se considera un problema de "otros" (individuo, colectividad, institucional) y la responsabilidad del control se desvía hacia otros (vecindario, comunidad, municipio, el Ministerio de Salud, etc.). Se carece de indicadores de riesgo precisos, por lo que no hay oportunidad para acciones de diagnóstico, tratamiento, prevención y control vectorial. Con intervenciones poco efectivas no hay control sostenible y sin compromiso político no hay recursos suficientes para enfrentar este problema sanitario. Este artículo aborda los desafíos para la prevención y el control del dengue en las Américas.

Dengue; Control de Enfermedades Transmisibles; Prevención de Enfermedades provides an additional difficulty for all strategies, because it requires not only continuity of actions, but also effectiveness. Although most community-based interventions emphasize this impact on behavioral changes of individuals, families and groups, they must also provoke changes in the behavior and responsibilities of institutions (health, education, municipal authorities, etc.) and other stakeholders. It is necessary to stress that preventive practices for dengue control, can only be modified or present when they are supported by efficient urban infrastructure.

Dengue is a complex disease that threatens the lives of millions of people in developing countries. Imprecise morbidity and mortality statistics undermine the study of factors associated with dengue transmission and its recognition as a major regional health problem. Dengue is perceived as a problem of "others" (individually, collectively and institutionally), and therefore responsibility for its control is passed on to others (neighbors, the community, municipality, health institution or other governmental agencies) and not fully appropriated by any. With no consistent or precise risk indicators (clinical, entomological, and epidemiological), there is little opportunity for timely diagnoses, treatment, health interventions or vector controls (poor surveillance). Solutions targeting only the vector reduce the impact of interventions. With ineffective interventions, there is no sustainable control and without population-based and political commitment, there are insufficient resources to address the problem.

\section{Contributors}

H. Gómez-Dantés designed the study, carried out a literature review and was responsible for writing in English the epidemiological and clinical elements as well as the design of the matrix. He also provided support to different sections with ideas and technical scientific contributions. J. R. Willoquet was responsible for writing the article and revising the English, contributing to the section about vectors and control, as well as providing support to the other sections with ideas and technical scientific contributions. 


\section{References}

1. Ehrenkranz NJ, Ventura AK, Cuadrado RR, Pond WL, Porter JE. Pandemic dengue in the Caribbean countries and the southern United States-past, present and potential problems. N Engl J Med 1971; 285:1460-9.

2. Soper FL. The elimination of urban yellow fever in the Americas through the eradication of Aedes aegypti. Am J Public Health 1963; 53:7-16.

3. Gubler DJ, Clark GC. Dengue/dengue hemorrhagic fever: the emergence of a global health problem. Emerg Infect Dis 1995; 1:55-7.

4. United Nations. World urbanization prospects, the 1999 revision. New York: United Nations; 2001.

5. Gubler D. Aedes and Aedes aegypti-borne disease control in the 1990s: top down or bottom up. Am J Trop Med Hyg 1989; 40:571-8.

6. Kay B, Sinh-Nam V. New strategy against Aedes aegypti in Vietnam. Lancet 2005; 365:613-7.

7. Pinheiro FP, Corber SJ. Global situation of dengue and dengue hemorrhagic fever, and its emergence in the Americas. World Health Stat Q 1997; 50: 161-9.

8. Gómez-Dantés H. El dengue en las Américas: un problema de salud regional. Salud Pública Méx 1991; 33:347-55.

9. Guha-Sapir D, Schimmer B. Dengue fever: new paradigms for a changing epidemiology. Emerg Themes Epidemiol 2005; 2:1.

10. Hales S, Wet N, Maindonald J, Woodward J. Potential effects of population and climate changes on global distribution of dengue fever: an empirical model. Lancet 2002; 360:830-4.

11. Briceño-García B, Gómez-Dantés H, Argot RE, Montesano R, Vazquez AL, Ibañez-Bernal S, et al. Potential risk for dengue hemorrhagic fever: the isolation of serotype Dengue 3 in Mexico. Emerg Infect Dis 1996; 2:133-5.

12. Hay SI, Myers M, Burke DS, Vaughn DW, Endy T, Anandal N, et al. Etiology of interepidemic periods of mosquito-borne disease. Proc Natl Acad Sci USA 2000; 97:9335-9.

13. Watts DM, Burke DS, Harrison BA, Whitmire RE, Nisalak A. Effect of temperature on the vector efficiency of Aedes aegypti for dengue 2 virus. Am J Trop Med Hyg 1987; 36:143-52.

14. Foo LC, Lim TW, Lee HL, Fang R. Rainfall, abundance of Aedes aegypti and dengue infection in Selangor, Malaysia. Southeast Asian. J Trop Med Public Health 1985; 16:560-8.

15. Aiken SR, Frost D, Leigh C. Dengue hemorrhagic fever and rainfall in peninsular Malaysia: some suggested relationships. Soc Sci Med 1980; 14: 307-16.

16. Depradine C, Lovell E. Climatological variables and the incidence of dengue fever in Barbados. Int J Environ Health Res 2004; 14:429-41.

17. Reiter P. Global warming and vector-borne disease in temperate regions and at high altitude. Lancet 1998; 351:839-40.

18. Hales S, Weinstein P, Woodward A. Dengue fever epidemics in the South Pacific region: driven by El Niño Southern Oscillation? Lancet 1996; 348: 1664-5.
19. Barrera R, Avila J, González S. Unreliable water supply of potable water and elevated Aedes aegypti larval indices: a causal relationship. J Am Mosq Control Assoc 1993; 9:189-95.

20. Rico-Hesse R. Molecular evolution and distribution of dengue viruses type 1 and 2 in nature. Virology 1990; 174:479-93.

21. Tabachnick WJ. The yellow fever mosquito: evolutionary genetics and arthropod-borne disease. Am Entomol 1991; 37:14-24.

22. Gómez-Dantés H, Ramos BB, Tapia-Conyer R. El riesgo de transmisión del dengue: un espacio para la estratificación. Salud Pública Méx 1995; 37 Suppl:88-97.

23. Koopman J, Prevots DR, Vaca MA, Gómez-Dantés $\mathrm{H}$. Determinants and predictors of dengue infection in Mexico. Am J Epidemiol 1999; 133:1168-78.

24. Chareonsook O, Foy HM, Teeraratkul A, Silarug N. Changing epidemiology of dengue hemorrhagic fever in Thailand. Epidemiol Infect 1999; 122:161-6.

25. Hayes CG, Phillips IA, Callahan JD, Griebenow WF, Hyams KC, Wu SJ. The epidemiology of dengue virus infection among urban, jungle and rural populations in the Amazon region of Peru. Am J Trop Med Hyg 1996; 55:459-63.

26. Escobar MJ, Gómez-Dantés H. Determinantes de la transmisión de dengue en Veracruz: un abordaje ecológico para su control. Salud Pública Méx 2003; 45:43-53.

27. van Benthem B, Vanwambeke S, Khantikul N, Burghoorn C, Panart K, Oskam L, et al. Spatial patterns of and risk factors for seropositivity for dengue infection. Am J Trop Med Hyg 2005; 72:201-8.

28. Dantes HG, Koopman JS, Addy CL, Zarate ML, Marin MA, Longini IM, et al. Dengue epidemics on the Pacific Coast of Mexico. Int J Epidemiol 1988; 17:178-86.

29. Ying-Chin K, Mei-Ju C, Shu-Mei Y. The predisposing and protective factors against dengue virus transmission by mosquito vector. Am J Epidemiol 1992; 136:214-20.

30. Reiter P, Lathrop S, Bunning M, Biggerstaff B, Singer D, Tiwari T, et al. Texas lifestyle limits transmission of dengue virus. Emerg Infect Dis 2003; 9:86-9.

31. Halstead SB. Dengue in the Americas and Southeast Asia: do they differ? Rev Panam Salud Pública 2006; 20:407-15.

32. Siquiera J, Martelli C, Maciel I, Oliveira R, Ribeiro M, Amorim F, et al. Household survey of dengue infection in Central Brazil: spatial point pattern analysis and risk factors assessment. Am J Trop Med Hyg 2004; 71:646-51.

33. Danis R, Rodriguez MH, Hernández AM. Gender related family head schooling and Aedes aegypti larval breeding risk in Southern Mexico. Salud Pública Méx 2002; 44:237-44.

34. Barrera R, Delgado N, Jiménez M, Villalobos I, Romero I. Estratificación de una ciudad hiperendémica en dengue hemorrágico. Rev Panam Salud Pública 2000; 8:225-33. 
35. Focks D, Daniels E, Haile DG, Keesling JE. A simulation model of the epidemiology of urban dengue fever: literature analysis, model development, preliminary validation, and samples of simulation results. Am J Trop Med Hyg 1995; 53:489-506.

36. García F, Muñoz ML, Lozano S, Fernandez SI, García RJ, Beatty B, et al. Large genetic distances among Aedes aegypti populations along the South Pacific coast of Mexico. Am J Trop Med Hyg 2002; 6:594-8.

37. Scott T, Amerasinghe P, Morrison A, Lorenz L, Clark G, Strickman D, et al. Longitudinal studies of Aedes aegypti in Thailand and Puerto Rico: blood feeding frequency. J Med Entomol 2000; 37:89-101.

38. Richardson J, Molina CA, Salazar MI, Black W. Quantitative analysis of dengue-2 virus RNA during the extrinsic incubation period in individual Aedes aegypti. Am J Trop Med Hyg 2006; 74:132-41.

39. Rico-Hesse R, Harrison LM, Salas RA, Tovar D, Nisalak A, Ramos C, et al. Origins of dengue type 2 viruses associated with increased pathogenicity in the Americas. Virology 1997; 230:244-51.

40. Loroño-Piña M, Farfán-Ale J, Zapata P-A, Rosado E, Flores FL, García RJ, et al. Introduction of the American/Asian genotype of Dengue 2 virus into the Yucatán state of Mexico. Am J Trop Med Hyg 2004; 71:485-92.

41. García-Rivera E, Rigau-Perez J. Dengue severity in the elderely in Puerto Rico. Rev Panam Salud Pública 2003; 13:363-8.

42. Mostorino R, Rosas A, Gutierrez V, Anaya E, Cobos M, García M. Manifestaciones clínicas y distribución geográfica de los serotipos del dengue en Perú, 2001. Rev Peru Med Exp Salud Pública 2002; 19:171-80.

43. Halstead S. Immune enhancement of viral infection. Prog Allergy 1982; 31:202-9.

44. Nisalak A, Endy T, Nimmannitya S, Kalayanarooj S, Thisayakorn U, Scott R, et al. Serotype-specific dengue virus circulation and dengue disease in Bangkok, Thailand from 1973-1999. Am J Trop Med Hyg 2003; 68:191-202.

45. Rigau-Perez J. Severe dengue: the need for new cases definitions. Lancet Infect Dis 2006; 6:297-302.

46. Beckett C, Kosasih H, Faisal I, Nurhayati, Tan R, Widjaja S, et al. Early detection of dengue infections using cluster sampling around index cases, Am J Trop Med Hyg 2005; 72:777-82.

47. Watts DM, Porter KR, Putvatana P, Vásquez B, Clamapa C, Hayes CG, et al. Failure of secondary infection with American genotype dengue 2 to cause dengue hemorrhagic fever. Lancet 1999; 354:1431-4.

48. Halstead S. Dengue. The case definition dilemma. A commentary. Pediatr Infect Dis J 2007; 26:291-2.

49. Hammond SN, Balmaceda A, Pérez L, Tellez Y, Saborío SI, Mercado JC, et al. Differences in dengue severity in infants, children and adults in a 3 year hospital-based study in Nicaragua. Am J Trop Med Hyg 2005; 73:1063-70.

50. Phuong C, Nhan N, Kneen R, Thuy P, Thien C, Nga $\mathrm{N}$, et al. Clinical diagnosis and assessment of severity of confirmed dengue infections in Vietnamese children: is the WHO classification system helpful? Am J Trop Med Hyg 2004; 70:172-9.
51. Halstead SB. More dengue, more questions. Emerg Infect Dis 2005; 11:740-1.

52. Navarrete-Espinosa J, Gómez-Dantés H, CelisQuintal G, Vázquez-Martinez JL. Clinical profile of dengue hemorrhagic fever cases in Mexico. Salud Pública Méx 2005; 47:193-200.

53. Gomez-Dantés H. Documenting outcomes, outputs and learning from ecohealth projects: dengue. Ottawa: International Development Research Centre; 2007. (Technical Report).

54. Guzmán MG, Pelegrino JL, Pumariega T, Vázquez S, González L, Kouri G, et al. Control externo de la calidad del diagnóstico serológico del dengue en laboratorios de países de las Américas, 1996-2001, Rev Panam Salud Pública 2003; 4:371-5.

55. Gubler DJ. The changing epidemiology of yellow fever and dengue, 1900 to 003: full circle? Comp Immunol Microbiol Infect Dis 2004; 27:319-30.

56. Iturrino-Monge R, Avila-Aguero M, Ávila-Aguero C, Moya T, Cañas-Coto A, Camacho K, et al. Seroprevalence of dengue virus antibodies in asymptomatic Costa Rican children, 2002-2003: a pilot study, Rev Panam Salud Pública 2006; 20:39-43.

57. Teixeira MG, Barreto M, Costa MC, Ferreira L, Vasconcelos P, Cairncross S, Dynamics of dengue virus circulation: a silent epidemic in a complex urban area. Trop Med Int Health 2002; 7:757-62.

58. Tun-Lin W, Kay B, Barnes A, Forsyth S. Critical examination of Aedes aegypti Indices: correlations with abundance. Am J Trop Med Hyg 1996; 54: 543-7.

59. Tun-Lin W, Kay B, Barnes A. Premise Condition Index: a tool for streamlining surveys of Aedes aegypti. Am J Trop Med Hyg 1995; 53:591-4.

60. Kay B, Prakash G, Andre RG. Aedes albopictus and other Aedes (Stegomyia) species in Fiji. J Am Mosq Control Assoc 1995; 11:230-4.

61. Hayes J, García-Rivera E, Flores RR, Suarez RG Rodríguez T, Coto R, et al. Risk factors for infection during a severe dengue outbreak in El Salvador in 2000. Am J Trop Med Hyg 2003; 69:629-33.

62. Kroeger A, Lenhart A, Ochoa M, Villegas E, Levy $\mathrm{M}$, Alexander N, et al. Effective control of dengue vectors with curtains and water container covers treated with insecticide in Mexico and Venezuela: cluster randomised trials. BMJ 2006; 332:1247-52.

63. Nathan MB. Critical review of Aedes aegypti control programs in the Caribbean and selected neighbouring countries. J Am Mosq Control Assoc 1993; 9:1-7.

64. Newton EAC, Reiter P. A model of the transmission of dengue fever with the evaluation of the impact of ultra-low volume (ULV) insecticide applications on dengue epidemics. Am J Trop Med Hyg 1992; 47:709-20.

65. Lloyd L, Winch P, Ortega-Canto J, Kendall C. Results of community-based Aedes aegypti control program in Merida, Yucatan, Mexico. Am J Trop Med Hyg 1992; 46:635-42.

66. Heinze C, Garrido MV, Kroeger A. What do community-based dengue control programmes achieve? A systematic review of published evaluations. Trans R Soc Trop Med Hyg 2007; 101:317-25. 
67. San Martin JL, Brathwaite-Dick O. La estrategia de gestión integrada para la prevención y control del dengue en las Américas. Rev Panam Salud Pública 2007; 18:55-63.

68. Kay B. Intersectorial approaches to dengue vector control. Gaoxiong Yi Xue Ke Xue Za Zhi 1994; 10 Suppl:S56-61.

69. Kroeger A, Nathan M. Dengue: setting the global research agenda. Lancet 2006; 368:2193-5.
70. Holmes E. Molecular epidemiology of dengue virus- the time for big science [Editorial]. Trop Med Int Health 1998; 3:855-6.

71. Deen J. The challenge of dengue vaccine development and introduction [Editorial]. Trop Med Int Health 2004; 9:1-3.

72. Tun-Lin W, Kay B, Barnes A. Understanding productivity, a key to Aedes aegypti surveillance. Am J Trop Med Hyg 1995; 53:595-601.

Submitted on $19 / \mathrm{Feb} / 2008$

Final version resubmitted on 26/May/2008 Approved on 16/Jun/2008 